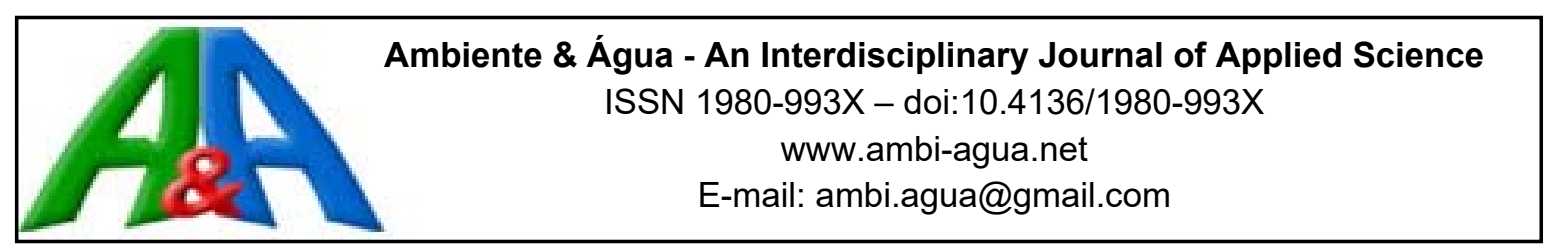

\title{
Caracterização de parâmetros de qualidade da água na área portuária de Barcarena, PA, Brasil
}

\author{
doi:10.4136/ambi-agua.1910
}

Received: 03 Apr. 2016; Accepted: 03 Mar. 2017

\begin{abstract}
Alba Rocio Aguilar Piratoba; Hebe Morganne Campos Ribeiro*; Gundisalvo Piratoba Morales; Wanderson Gonçalves e Gonçalves
\end{abstract}

\author{
Universidade do Estado do Pará (UEPA), Belém, PA, Brasil \\ *Autor correspondente: e-mail: hebemcr@gmail.com, \\ alba_roapt@hotmail.com,gundymorales@gmail.com, \\ wanderson_goncalves@rocketmail.com
}

\section{RESUMO}

Empresas no pólo industrial do município de Barcarena-PA utilizam matérias primas, insumos e energia e geram resíduos sólidos, efluentes industriais e esgoto doméstico que são lançados em corpos receptores, alterando as suas características físicas, químicas e microbiológicas. Visando determinar a influência das empresas localizadas no pólo industrial de Barcarena, foi realizado um estudo em um trecho do Rio Pará que sofre influência do lançamento de efluentes industriais das empresas em operação. Para tal, foram selecionados quatro pontos amostrais onde foram realizadas duas campanhas, sendo uma realizada no período menos chuvoso e outra no período chuvoso. Em cada campanha, foram coletadas amostras simultaneamente nos quatro pontos de amostragem durante um período de 12 horas, com intervalos de 90 minutos, iniciando e terminando a coleta no final da vazante. Foram coletadas 36 amostras nos 4 pontos selecionados em cada campanha de amostragem da maré, totalizando 72 amostras nas duas campanhas realizadas. Nas amostras, foram quantificadas variáveis hídricas como: $\mathrm{pH}$, temperatura, condutividade, sólidos totais dissolvidos (STD), cor, sódio, cálcio, potássio, cloreto, alcalinidade e dureza. Os dados foram analisados utilizando o teste estatístico ANOVA de dois fatores com a finalidade de observar se as diferentes variáveis analisadas apresentavam diferenças significativas entre os pontos de amostragem e a sazonalidade, usando nível de significância de 95\%. Foi também calculado o Índice de Qualidade de Água (IQA-CETESB). Os testes estatísticos mostraram que a localização dos pontos de amostragem não exerceu influência nos teores médios de $\mathrm{pH}$, porém houve influência significativa para as demais variáveis. Quanto à sazonalidade, houve diferença significativa em praticamente todas as variáveis, com exceção do cloreto e alcalinidade. As amostras de águas apresentaram IQA de qualidade ótima e boa.

Palavras-chave: água, ANOVA, efluentes.

\section{Characterization of water quality parameters in the port area of Barcarena, PA, Brazil}

\begin{abstract}
Companies in the industrial hub of Barcarena-PA city use raw materials, supplies and energy that generate solid waste, industrial effluents and domestic sewage that are released in
\end{abstract}


water bodies, changing their physical, chemical and microbiological characteristics. To determine the influence of the companies located in the industrial hub of Barcarena, a study was conducted in a stretch of Pará River under the influence of industrial effluents released by operating companies. Four sampling sites were therefore selected where two campaigns were conducted, one held in the less rainy period and another in the rainy season. Within each field, samples were collected simultaneously at four sample points over a period of 12 hours with 90 minute intervals starting and ending at the end of the ebb tide. We collected 36 samples in the 4 selected points in each sampling campaign of the tide, totaling 72 samples in the two campaigns. Samples were analyzed for $\mathrm{pH}$, temperature, conductivity, total dissolved solids (STD acronym in Portuguese), color, sodium, calcium, potassium, chloride, alkalinity and toughness. The ANOVA test of two factors was used in order to observe whether the variables showed significant differences between the sampling points and seasonality at a 95\% significance level. The Water Quality Index (IQA-CETESB) was also calculated. Statistical tests showed that the location of the sampling sites had no influence on the average levels of $\mathrm{pH}$, however there was a significant influence on the other variables. Regarding seasonality, there was no significant difference in all variables, except for chloride and alkalinity. The water samples showed IQA of excellent and good quality.

Keywords: ANOVA, effluent, water.

\section{INTRODUÇÃO}

A água é um dos recursos naturais mais importantes no planeta e até bem pouco tempo era considerado como um bem infinito. $\mathrm{O}$ aumento da população e todos os fatores atrelados com este crescimento têm ocorrido em detrimento da degradação dos recursos hídricos por causa de seus usos múltiplos, destacando entre eles a agricultura, o abastecimento público, a pecuária, a indústria, a geração de energia, o saneamento básico, a recreação e o lazer (Zhang et al., 2010; FAO, 2015). Embora a maior parte da superfície da Terra esteja ocupada de água, somente cerca de $2,5 \%$ são de água doce, com um mínimo de $0,06 \%$ correspondente à água dos rios, lagos, biomassa entre outros. O restante da água doce está no subsolo e nas calotas polares sendo estas duas de difícil acesso (Esteves, 2011).

Segundo Von Sperling (2007), a qualidade de uma água está determinada por fenômenos naturais e antrópicos exercidos na bacia hidrográfica. A água é o solvente universal, transportando gases, elementos e substâncias, e compostos orgânicos dissolvidos que são à base da vida no planeta (Tundisi e Matsumura-Tundisi, 2008). Na natureza, o ciclo hidrológico é o mecanismo que permite a mudança de estado físico e permite o contato com diferentes ambientes; dentro das etapas do ciclo é conferida uma natureza química à água. As características da água natural estão determinadas pelas substâncias químicas dissolvidas, diretamente relacionadas com a geoquímica do solo e das rochas nas bacias hidrográficas que drenam os rios e lagos (Von Sperling, 2007; Drever, 1988). Corpos de águas como os rios são sistemas que transportam substâncias, podendo apresentar diferentes concentrações de compostos nas nascentes, no meio e no baixo curso de um rio (Zhang et al., 2010).

De acordo com a legislação, a definição da qualidade da água faz referência ao tipo de uso ao qual se destina, e estipula os padrões de qualidade na resolução 357 do Conselho Nacional do Meio Ambiente (CONAMA) de 2005 e suas modificações nas resoluções 410 de 2009 e 430 de 2011. Os parâmetros são definidos em limites aceitáveis das substâncias presentes de acordo com o uso da água.

No caso específico de Barcarena-PA, desde os anos 80, às margens do Rio Pará expande-se um pólo industrial, onde na atualidade estão instaladas empresas com beneficiamento de

Rev. Ambient. Água vol. 12 n. 3 Taubaté - May / Jun. 2017 
alumínio e caulim e outros empreendimentos tais como Albras/Alunorte, Usina Siderúrgica do Pará-USIPAR e Rio Capim Caulim \& Pará Pigmentos S.A., Alubar, unidade de produção de fertilizantes da Bunge (CDP, 2010), sem deixar de lado a implantação do Porto de Vila do Conde.

Neste estudo, o objetivo foi fazer a determinação da qualidade da água em um trecho do rio Pará no município de Barcarena-PA e avaliar a influência das indústrias localizadas no pólo industrial.

Muitos estudos da qualidade da água são realizados mundialmente, como os realizados por Carreón et al. (2013) na lagoa Yuriria no México nos períodos de 2005 e 2009-2010 com a finalidade de avaliar variações espaciais e temporais das características da água. Em outro estudo realizado, Goher et al. (2014), no Canal de Ismaília no rio Nilo no Egito, avaliaram o índice de qualidade da água (IQA) e de alguns metais pesados. Chán Santisteban e Peña (2015) avaliaram alguns parâmetros de qualidade da água numa bacia da Guatemala que abastece a cidade para o consumo urbano. No Brasil também existem estudos como os de Bucci e Oliveira (2014) que avaliaram a qualidade da água e o estado trófico na Represa Dr. João Penido em Juiz de Fora- MG. Lobato et al. (2015) avaliaram a qualidade da água no lago Tucuruí- PA. Outro estudo de Oliveira e Cunha (2014), realizado no rio Jari - AP, avaliou a variabilidade da qualidade da água sob influência da precipitação mensal. Observa-se que estes estudos são importantes fontes de informações para conhecer as características e os efeitos de ações naturais e antrópicas exercidas nos corpos de água.

\section{METODOLOGIA}

A área de estudo localiza-se no município de Barcarena, pertencente à região metropolitana de Belém, PA, Brasil. Tal município limita-se ao Norte com a Baía de Guajará e Município de Belém, ao Sul com os Municípios de Moju e Abaetetuba, a Leste com a Baía de Guajará e Município de Acará e a Oeste com a Baía do Marajó (Município de Barcarena, 2011). Segundo a classificação de Köppen possui um clima tropical chuvoso de tipo Afi, com a presença de chuvas durante todo o ano (INMET, 2012). A média da precipitação pluvial anual é de $2500 \mathrm{~mm}$. Essas mudanças são, segundo Cohen et al. (2007), decorrentes em parte do desaparecimento da formação de nuvens baixas e médias formadas a partir de aerossóis de queimadas. A vegetação é tropical com Floresta Densa nas áreas elevadas; vegetação de Várzeas típicas de áreas inundáveis e Floresta Secundária (Ribeiro et al., 2013), ecossistemas que sofrem contínuas modificações pela presença do complexo industrial na localidade. $\mathrm{Na}$ porção continental, os solos predominantes são o Latossolo Amarelo distrófico, o Podzol Hidromórfico e Concrecionário Laterítico indiscriminado distrófico, textura indiscriminada (EMBRAPA, 2013). Entre as atividades produtivas destaca-se a agricultura, pesca artesanal e a indústria, principalmente pela locação de empresas com beneficiamento de alumínio implantado desde a década de 80 e em contínuo crescimento, decorrente de atividades minero-metalúrgicas e portuárias, sendo esta última devido à criação do Porto da Vila do Conde (Paz et al., 2011).

Foram selecionados quatro pontos de amostragem P-01, P-02, P-03 e P-04, denominados e georreferenciados como P-01 Rio Arienga (S 744945,8 O 9822509,3 UTM); P-02 na frente das empresas Pará Pigmentos S.A. (PPSA) e Imerys Rio Capim Caulim (IRCC) (S 747086,9 O 9826412,2 UTM); P-03 frente da Vila do Conde (S 748593,8 O 9828178,9 UTM) e P-04 na frente da praia do Caripi (S 754846,6 O 9835755,1 UTM). A Figura 1 mostra a localização dos pontos de amostragem do corpo hídrico estudado. A seleção dos pontos de amostragem foi realizada com a finalidade de comparar estatisticamente os diferentes parâmetros analisados no corpo hídrico. 


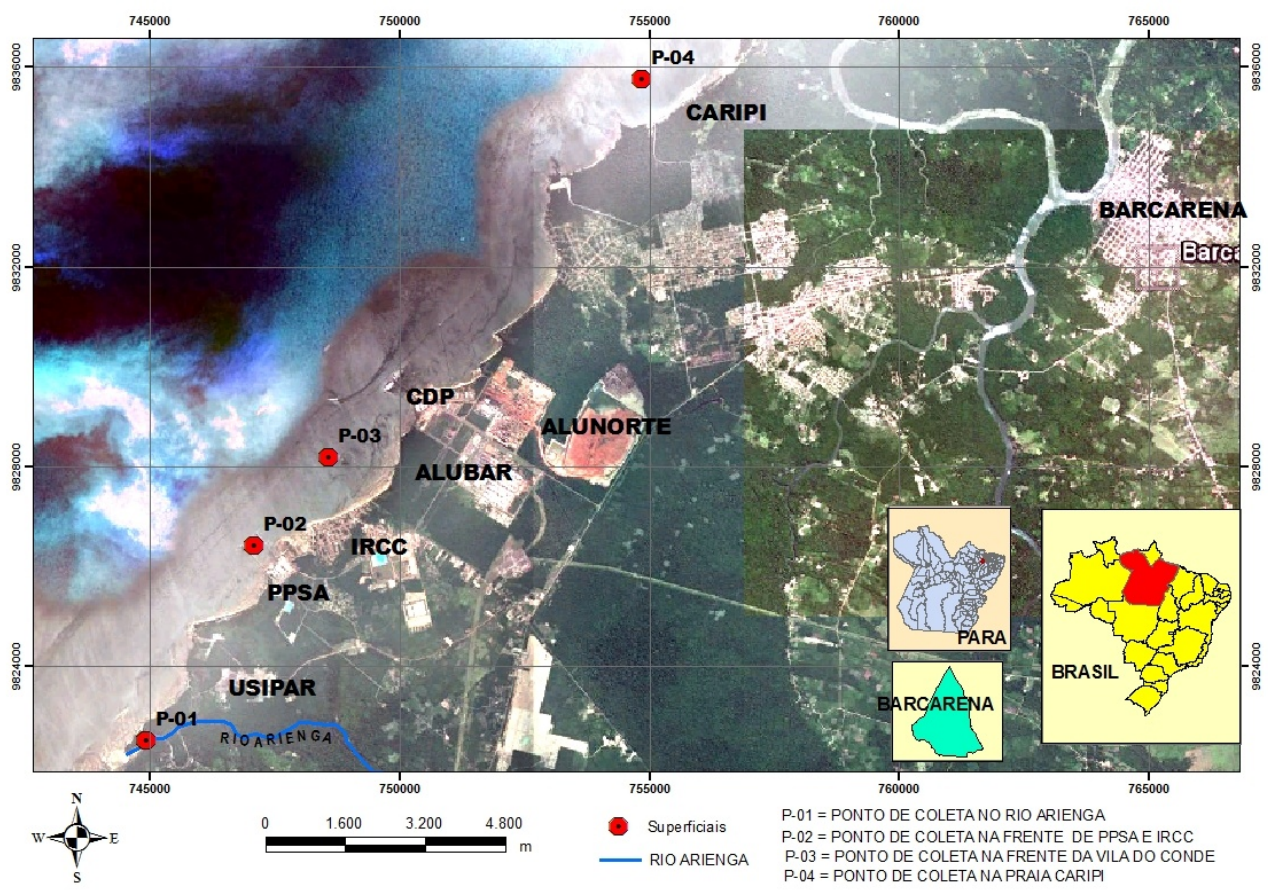

Figura 1. Mapa de localização da área de estudo e dos pontos de amostragem, onde (P-01) Rio Arienga, (P-02) frente de PPSA e IRCC, (P-03) frente da Vila do Conde e P-04 frente na praia Caripi.

A amostragem foi realizada considerando um período sazonal. A primeira foi realizada em dezembro de 2011 (período menos chuvoso) com uma temperatura máxima de $33,3^{\circ} \mathrm{C}$ e a mínima de $22,8^{\circ} \mathrm{C}$, ausência de precipitações e insolação de 9,4 . Por outro lado, a segunda amostragem foi realizada em junho de 2012 (período mais chuvoso) com as temperaturas máxima de $31,4^{\circ} \mathrm{C}$ e mínima de $21,4^{\circ} \mathrm{C}$, a precipitação de $1 \mathrm{~mm}$ e insolação com valor 0 (INMET, 2012).

Esta amostragem foi simultânea nos quatro pontos de coleta em um período de 12 horas contínua, com intervalos a cada 90 minutos, durante um ciclo de maré, iniciando às 6:00 horas e finalizando às 18:00 horas. A amostragem foi realizada de acordo como as normas da Associação Brasileira de Normas Técnicas e da Companhia Ambiental do Estado de São Paulo - CETESB. Cada coleta foi realizada manualmente em garrafas de polietileno de diferentes volumes devidamente lavadas e esterilizadas em autoclaves. Em campo, as garrafas foram acondicionadas com água do próprio corpo hídrico e colocadas em contra corrente ao fluxo da correnteza para coletar a amostra, e finalmente foram armazenadas em caixas de isopor em refrigeração (ABNT, 1987). A temperatura foi medida em campo usando termômetro digital da marca HANNA HI 98501. As medidas de $\mathrm{pH}$ e condutividade foram realizadas utilizando equipamentos da marca DIGIMED, pH-metro DM 2P e condutivímetro DM 3P. O condutivímetro também foi utilizado para a medida de sólidos totais dissolvidos. As amostras foram transportadas ao laboratório de Hidrocarbonetos (LABOHI) do Centro de Ciências Naturais e Tecnologia da Universidade do Estado do Pará. No laboratório, foram realizadas a determinação de cor com o colorímetro DM-COR. Para a análise de sódio $(\mathrm{Na})$, cálcio $(\mathrm{Ca})$ e potássio $(\mathrm{K})$, utilizou-se o fotômetro de chama DM- 62, com equipamentos devidamente calibrados. O cloreto foi determinado por titulação com nitrato de prata, conforme a norma NBR 13797. A alcalinidade foi obtida pelo método de titulação da norma técnica L5. 102, e a dureza pela titulação com EDTA, norma técnica da CETESB L5.124. Os coliformes termotolerantes foram determinados pelo método de Tubos Múltiplos de acordo com o método 
estabelecido pelo Standard Methods for the Examination of Water \& Wastewater method 9230 - B (APHA et al., 1995).

Para a sistematização dos resultados foi utilizada a estatística descritiva, tabulando a mediana e o desvio padrão (Tabela 1). O tratamento estatístico para a comparação dos dados foi realizado pelo teste de Análise da Variância (ANOVA) de dois fatores com repetição. $\mathrm{O}$ teste ANOVA é um teste de hipótese para comparar as médias de duas ou mais populações. $\mathrm{Na}$ ANOVA com fator duplo, os fatores A e B podem influenciar na variável dependente de forma isolada (efeitos principais) e de forma combinada, efeito de uma combinação específica dos fatores A e B (Lapponi, 2005). Para este estudo, os fatores foram definidos assim: o fator sazonalidade, que faz referência às duas campanhas de coleta realizadas; o fator localização, que são os quatro pontos de amostragem distribuídos espacialmente na área de estudo, e as interações dos dois fatores formam oito grupos com nove observações (número de amostras coletadas em cada ponto). Segundo o anterior, os testes de hipóteses são três hipóteses nulas: Ho1 - que não há efeito pela sazonalidade (duas campanhas de coleta), Ho2 - que não há efeito entre os quatro pontos de amostragem e $\mathrm{Ho} 3$ - que não há combinação entre os efeitos sazonalidade e pontos de amostragem. As hipóteses alternativas são $\mathrm{H}_{1}$, que há efeito em cada um dos três casos. Este teste de hipóteses é para cada um dos parâmetros analisados, considerado um nível de significância de $95 \%$.

O Índice de Qualidade de Água (IQA) corresponde a um número que varia de 0 a 100 , onde o cálculo foi executado de acordo com o que recomenda Von Sperling (2007), considerando nove parâmetros (temperatura, $\mathrm{pH}$, oxigênio dissolvido, demanda bioquímica de

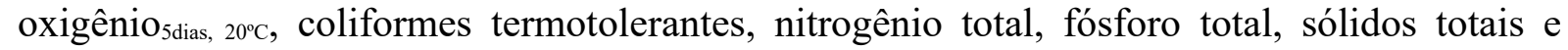
turbidez). A fórmula adaptada pela CETESB é indicada por Von Sperling (2007) para o cálculo de IQA (Equação 1).

$$
\mathrm{IQA}=\prod_{i=1}^{\mathrm{n}} \mathrm{q}_{\mathrm{i}}^{\mathrm{w}_{\mathrm{i}}}
$$

em que:

IQA: índice de qualidade de água, variando entre 0 e 100;

qi: qualidade do i-ésimo parâmetro, variando entre 0 e 100 de acordo com a curva média de variação de qualidade - uma função de sua medida ou concentração;

wi: peso correspondente ao i-ésimo parâmetro, variando entre 0 e 1; e

i: número do parâmetro, variando entre 1 e 9 ( $n=9$, que é o número de parâmetros envolvidos no cálculo de IQA).

A partir das fórmulas fornecidas por Von Sperling (2007), criou-se uma planilha para o cálculo das qualidades de cada parâmetro no software Excel, de modo a automatizá-lo.

\section{RESULTADOS E DISCUSSÃO}

\subsection{Análise de variância (ANOVA)}

As médias aritméticas e os desvios padrão estão relacionados na Tabela 1 para cada um dos parâmetros determinados das duas campanhas de coleta nos quatro pontos de amostragem. Segundo o teste estatístico ANOVA resumido na Tabela 2, são mostrados os resultados das análises de variância para cada um dos parâmetros analisados. Para todos os parâmetros, o F crítico das interações do fator ponto de coleta e para o fator sazonalidade foram 3,99; 2,748 e 2,748 , respectivamente. $\mathrm{Na}$ interpretação dos dados quando o $\mathrm{F}$ observado é menor que o $\mathrm{F}$ crítico, a hipótese nula é aceita, também comprovado quando o valor-p é menor que a probabilidade, que neste estudo é $\alpha=0,05$. 
Tabela 1. Médias (Med.), desvio padrão (DP) e número de valores (N) dos parâmetros analisados nas duas campanhas em quatro pontos de coleta.

\begin{tabular}{|c|c|c|c|c|c|c|c|c|c|c|c|c|}
\hline & \multicolumn{12}{|c|}{ Período menos chuvoso } \\
\hline & \multicolumn{3}{|c|}{ PONTO 1} & \multicolumn{3}{|c|}{ PONTO 2} & \multicolumn{3}{|c|}{ PONTO 3} & \multicolumn{3}{|c|}{ PONTO4 } \\
\hline & $\mathrm{N}$ & Med. & DP & $\mathrm{N}$ & Med. & DP & $\mathrm{N}$ & Med. & DP & $\mathrm{N}$ & Med. & DP \\
\hline $\mathrm{pH}$ & 9 & 7,02 & 0,25 & 9 & 7,01 & 0,16 & 9 & 7,18 & 0,05 & 9 & 7,04 & 0,21 \\
\hline $\mathrm{T}\left({ }^{\circ} \mathrm{C}\right)$ & 9 & 30,4 & 0,85 & 9 & 30,5 & 0,7 & 9 & 30,7 & 0,86 & 9 & 31,1 & 0,44 \\
\hline Cloreto (mg L-1) & 9 & 0,26 & 0,06 & 9 & 0,41 & 0,17 & 9 & 0,41 & 0,16 & 9 & 0,44 & 0,13 \\
\hline $\mathrm{CE}\left(\mu \mathrm{Scm}^{-1}\right)$ & 9 & 49,57 & 4,32 & 9 & 68,08 & 16,38 & 9 & 46,08 & 4,85 & 9 & 45,08 & 0,86 \\
\hline $\operatorname{STD}\left(\mathrm{mg} \mathrm{L}^{-1}\right)$ & 9 & 16,40 & 1,48 & 9 & 27,05 & 7,38 & 9 & 16,87 & 2,17 & 9 & 16,28 & 0,40 \\
\hline Cor $\left(\mathrm{mgPt} \mathrm{L}{ }^{-1}\right)$ & 9 & 46,83 & 8,12 & 9 & 35,46 & 3,68 & 9 & 42,43 & 3,20 & 9 & 35,56 & 4,21 \\
\hline $\mathrm{Na}\left(\mathrm{mg} \mathrm{L}^{-1}\right)$ & 9 & 2,89 & 0,29 & 9 & 6,79 & 3,80 & 9 & 2,68 & 0,53 & 9 & 2,69 & 0,19 \\
\hline $\mathrm{K} m g\left(\mathrm{~L}^{-1}\right)$ & 9 & 1,40 & 0,10 & 9 & 1,12 & 0,30 & 9 & 1,27 & 0,32 & 9 & 1,27 & 0,12 \\
\hline Alcalinidade $\left(\mathrm{mg} \mathrm{L}^{-1} \mathrm{CaCO}_{3}\right)$ & 9 & 16,36 & 1,09 & 9 & 17,57 & 1,35 & 9 & 18,51 & 1,18 & 9 & 18,11 & 0,98 \\
\hline Dureza $\left(\mathrm{mg} \mathrm{L}^{-1}\right)$ & 9 & 16,99 & 1,04 & 9 & 16,21 & 0,78 & 9 & 16,73 & 0,78 & 9 & 17,52 & 1,71 \\
\hline \multirow[t]{2}{*}{ Cálcio $\left(\mathrm{mg} \mathrm{L}^{-1}\right)$} & 9 & 1,89 & 0,79 & 9 & 2,13 & 0,39 & 9 & 2,59 & 0,75 & 9 & 2,51 & 0,27 \\
\hline & \multicolumn{12}{|c|}{ Período chuvoso } \\
\hline $\mathrm{pH}$ & 9 & 7,34 & 0,17 & 9 & 7,39 & 0,03 & 9 & 7,31 & 0,03 & 9 & 7,22 & 0,04 \\
\hline $\mathrm{T}\left({ }^{\circ} \mathrm{C}\right)$ & 9 & 29,4 & 0,32 & 9 & 29,8 & 0,47 & 9 & 30,1 & 0,39 & 9 & 30,1 & 0466 \\
\hline Cloreto $\left(\mathrm{mg} \mathrm{L}^{-1}\right)$ & 9 & 0,23 & 0,05 & 9 & 0,42 & 0,05 & 9 & 0,38 & 0,05 & 9 & 0,37 & 0,04 \\
\hline $\mathrm{CE}\left(\mu \mathrm{Scm}^{-1}\right)$ & 9 & 35,77 & 2,56 & 9 & 42,60 & 2,50 & 9 & 43,22 & 2,91 & 9 & 43,09 & 2,14 \\
\hline $\operatorname{STD}\left(\mathrm{mg} \mathrm{L}^{-1}\right)$ & 9 & 10,38 & 0,70 & 9 & 12,66 & 0,43 & 9 & 13,35 & 1,25 & 9 & 12,76 & 0,58 \\
\hline Cor $\left(m g P t ~ L^{-1}\right)$ & 9 & 59,40 & 12,51 & 9 & 48,29 & 2,87 & 9 & 50,21 & 4,02 & 9 & 96,11 & 5,42 \\
\hline $\mathrm{Na}\left(\mathrm{mg} \mathrm{L}^{-1}\right)$ & 9 & 1,54 & 0,21 & 9 & 2,83 & 0,41 & 9 & 3,28 & 1,58 & 9 & 3,40 & 0,44 \\
\hline $\mathrm{K}\left(\mathrm{mg} \mathrm{L}^{-1}\right)$ & 9 & 1,27 & 0,41 & 9 & 1,58 & 0,20 & 9 & 1,59 & 0,41 & 9 & 1,96 & 0,29 \\
\hline Alcalinidade $\left(\mathrm{mg} \mathrm{L}^{-1}\right)$ & 9 & 17,44 & 1,45 & 9 & 16,70 & 0,96 & 9 & 17,03 & 1,02 & 9 & 17,71 & 1,41 \\
\hline Dureza $\left(\mathrm{mg} \mathrm{L}^{-1}\right)$ & 9 & 12,55 & 1,18 & 9 & 14,64 & 1,04 & 9 & 14,38 & 0,78 & 9 & 14,64 & 1,04 \\
\hline Cálcio $\left(\mathrm{mg} \mathrm{L}^{-1}\right)$ & 9 & 0,57 & 0,1 & 9 & 0,82 & 0,08 & 9 & 0,78 & 0,14 & 9 & 0,81 & 0,08 \\
\hline
\end{tabular}

$\mathrm{O}$ pH é uma variável abiótica importante nos ecossistemas aquáticos de difícil interpretação pela quantidade de fatores que o podem afetar (Esteves, 2011). O valor médio do $\mathrm{pH}$ foi de 7,01 a 7,18 no período menos chuvoso, e de 7,22 a 7,39 no período chuvoso como 
mostrado na Tabela 1. Embora os valores do $\mathrm{pH}$ estejam na faixa da neutralidade, para o período menos chuvoso os valores de $\mathrm{pH}$ são mais baixos que na época de chuva, como pode ser observado na Figura 2(a). Estes teores são maiores se comparados com os valores obtidos por Pereira et al. (2007) no Rio Murucupi no mesmo município com características ácidas e valores entre 4,35 a 6,15. Pontes et al. (2012), observaram na microbacia do Córrego Banguelo no Estado de Minas Gerais que a maioria dos pontos monitorados apresentou água mais ácida também no período de chuvas, o que pode estar associada ao aumento no teor de ácidos orgânicos. Resultados similares também foram encontrados por Santi et al. (2012) no Igarapé São Francisco, no Estado do Acre, durante o período de alta pluviosidade. Os autores enfatizam que os resultados são explicados pelo fato das águas da precipitação atmosférica serem mais ácidas. Porém, deve-se considerar a descrição de Sioli $(1956 ; 1957 ; 1960)$ dos rios amazônicos em estado natural que apresentam diferentes valores de $\mathrm{pH}$. Assim, os rios de águas brancas estão entre 6,2 e 7,2, os rios de águas claras entre 4,5 e 7,8 e os rios de águas pretas entre 3,8 e 4,9. Por outro lado, os valores de $\mathrm{pH}$ podem ser alterados ao longo do rio, caso concreto do Rio Amazonas, que de um $\mathrm{pH}$ de 4,0 eleva-se até 7,8 praticamente no encontro com águas marinhas (Esteves, 2011). Segundo o teste ANOVA, a localização dos pontos não tem influência significativa no valor médio do $\mathrm{pH}$ aceitando a hipótese nula. Estudos realizados na área mostram que o $\mathrm{pH}$ é influenciado pela maré, pois pode funcionar como agente depurador nos rios da região quando estes são afetados por descargas de efluentes (Pereira et al., 2007). Entretanto, a sazonalidade e a sua interação com o fator "ponto de amostragem", estatisticamente, têm influência significativa nos teores médios do $\mathrm{pH}$, aceitando as hipóteses alternativas. De acordo com Von Sperling (2007), fatores naturais como a dissolução de rochas e a fotossíntese, ou fatores antrópicos como os esgotos domésticos e industriais afetam o $\mathrm{pH}$. Segundo Silva (2008), com o aumento das chuvas o $\mathrm{pH}$ tende a subir, pois aumenta a diluição de compostos dissolvidos e há um escoamento maior. Na maioria das águas naturais, o sistema carbonato controla o pH (Drever, 1988). Esteves (2011) afirma que as reações de íons carbonato e bicarbonato com a molécula de água elevam o pH. Em um estudo de Miranda et al. (2009), realizado no rio Tapajós em Santarém- PA, encontraram teores de $\mathrm{pH}$ entre 6,6 e 7,8, concluindo conformidade com a legislação estabelecida pelo CONAMA 357. Outro estudo realizado por Alves et al. (2012) em águas superficiais no rio Arari na ilha de Marajó-PA, encontraram inconformidades com a legislação nos valores de $\mathrm{pH}$ que estavam entre 3,3 e 6,22. Os teores de $\mathrm{pH}$ do presente estudo estão dentro dos padrões permitidos pelo CONAMA/357 para águas doces classes I, II e III, que aceita valores entre a faixa de 6,0 a 9,0 (CONAMA, 2005).

Segundo Boesch (2002) e Esteves (2011), a condutividade elétrica é um parâmetro que pode mostrar modificações na composição dos corpos d'água, mas não especifica quantidades e componentes. É um parâmetro importante para controlar e determinar o estado e a qualidade de água (Piñeiro Di Blasi et al., 2013). Existe uma correlação estatística entre a condutividade da água e a concentração de diversos elementos e íons (Tundisi e Matsumura-Tundisi, 2008). De acordo com Esteves (2011), nas regiões tropicais a condutividade está relacionada com as características geoquímicas da região e condições climáticas (periodicidade de precipitações). Rios que podem ter a mesma nascente e diferentes drenagens apresentam diferenças na condutividade elétrica (Frančišković-Bilinski, et al. 2013). Os resultados na área de estudo mostraram que os teores de condutividade mudam de 45,08 a $68,08 \mu \mathrm{S} \mathrm{cm}^{-1}$ no período menos chuvoso e de 35,77 a $43,22 \mu \mathrm{S} \mathrm{cm}^{-1}$ no período chuvoso (Tabela 1). Na Figura 2 (b) pode ser observado que no período menos chuvoso, os teores da condutividade são maiores especialmente no ponto P-02 mais próximo do pólo industrial de Barcarena e com maior influência dos efluentes lançados pelas indústrias e pela comunidade da Vila do Conde. O uso do solo pode modificar diretamente a composição de uma água refletindo-se na condutividade elétrica (Esteves, 2011, 1998; Von Sperling, 2005). Por meio das análises estatísticas, 
comprovou-se que a sazonalidade, a localização dos pontos de amostragem e a interação entre eles afetam significativamente os teores médios da condutividade elétrica, rejeitando as hipóteses nulas. Segundo Esteves (2011), a condutividade elétrica muda com a sazonalidade sendo menor no período chuvoso por causa do aumento do fator de diluição dos íons, não obstante o lançamento de efluentes industriais poderem elevar os valores da condutividade elétrica independentemente da sazonalidade. Não existe um padrão de condutividade na legislação, porém, de acordo com Von Sperling (2007), as águas naturais apresentam teores de condutividade na faixa de 10 a $100 \mu \mathrm{S} \mathrm{cm}^{-1}$, e em ambientes poluídos por esgotos domésticos ou industriais os valores podem chegar até $1000 \mu \mathrm{S} \mathrm{cm}^{-1}$. Em um estudo realizado por Alvarenga et al. (2012) em uma microbacia afluente do Rio Paraíba do Sul- SP, em um período chuvoso e dois não chuvosos reportaram valores de condutividade de 26,00 a $50,10 \mu \mathrm{S} \mathrm{cm}^{-1}$; neste estudo observou-se que um dos períodos secos apresentou baixos teores de condutividade comparado com os outros períodos de coleta. Em uma avaliação da qualidade da água realizado por Marmontel e Rodrigues (2015) em nascentes de diferentes coberturas vegetais no Córrego Pimenta- SP encontraram teores de 10,7 a $139,0 \mu \mathrm{S} \mathrm{cm}^{-1}$ no período seco e de 13,2 a $149,0 \mu \mathrm{S} \mathrm{cm}^{-1}$ no período chuvoso, mostrando um comportamento similar aos deste estudo, encontrando os maiores teores no período chuvoso. Valores médios reportados por Sioli (1984) da condutividade em três rios da região Amazônica foram de $57 \mu \mathrm{S} \mathrm{cm}^{-1}$ para o Rio Solimões, $22 \mu \mathrm{Scm}^{-1}$ para o Rio Negro e $21 \mu \mathrm{Scm}^{-1}$ para o Rio Tarumã-Mirim. Nos dois últimos casos, os valores são inferiores se comparados com os teores médios obtidos no presente estudo.

A temperatura é o parâmetro que faz a medição da intensidade de calor, refletindo o grau de aquecimento das águas e da radiação solar, e depende de fatores como clima, composição geológica, condutividade elétrica das rochas, dentre outras (Matic et al., 2013). Os teores médios da temperatura neste estudo para o período menos chuvoso estão entre 30,4 a $31,1^{\circ} \mathrm{C}$, e para o período chuvoso entre 29,4 e $30,1^{\circ} \mathrm{C}$ (Tabela 1), mostrando uma estabilidade durante todo o ano característico da região equatorial (Esteves, 2011; Matic et al., 2013). Estatisticamente, a localização e a sazonalidade tiveram influência significativa nos teores médios da temperatura aceitando as hipóteses alternativas como pode ser visto na Tabela 2 . Porém, a interação entre eles não tem influência aceitando a hipótese nula. Entre as duas campanhas de coleta pode ser observado uma variação de $1^{\circ} \mathrm{C}$ sendo maior no período menos chuvoso conforme a Figura 2 (c). As variações de temperatura nos corpos d'água naturais podem ser sazonais e diurnas de acordo com estudos de Sá Filho (2010) e estão associadas com as estações do ano - Bucci et al. (2015). Assim, estudos realizados em regiões que apresentam maior variação sazonal da temperatura influenciam na temperatura dos corpos hídricos, como o de Souza et al. (2015) que em um trecho da bacia Ribeirão Ubá- MG encontraram teores que variavam de 20,6 até $24^{\circ} \mathrm{C}$ e a elevação da temperatura da água foi correlacionada com a temperatura do ar. Na época de maior precipitação, a nebulosidade aumenta e dificulta a entrada dos raios solares às superfícies dos corpos d'água, o que não sucede no período menos chuvoso, pois o tempo de incidência dos raios solares é maior (Sá Filho, 2010). A temperatura é um parâmetro que também permite determinar se há poluição térmica pela descarga de efluentes (Von Sperling, 2007; Sanchez, 2006). Como diversos corpos hídricos são receptores de efluentes, a resolução do CONAMA 430 estabelece como temperatura máxima para o lançamento de efluentes, $40^{\circ} \mathrm{C}$. Observou-se que nos pontos de amostragem (CONAMA, 2011), o ponto P-01 tem um teor médio menor que nos pontos P-02, P-03 e P-04, pontos estes que estão localizados em áreas abertas e livres da influência vegetal, que poderiam impedir a entrada dos raios solares. Para Madden et al. (2013) as descargas de efluentes mudam a temperatura dos ecossistemas aquáticos representando ameaça para a biota aquática. Por outro lado, na coluna d'água a temperatura diminui com a profundidade de um corpo hídrico e tem correlação com outros parâmetros (Malheiros et al., 2012).

Rev. Ambient. Água vol. 12 n. 3 Taubaté - May / Jun. 2017 
Tabela 2.Teste estatístico ANOVA de um fator F.

\begin{tabular}{|c|c|c|c|c|c|c|c|c|c|}
\hline & \multicolumn{3}{|c|}{ Interações } & \multicolumn{3}{|c|}{ Sazonalidade } & \multicolumn{3}{|c|}{ Pontos } \\
\hline & $\mathrm{F}$ & valor-p & $\begin{array}{l}\text { Hipótese } \\
\text { aceita }\end{array}$ & $\mathrm{F}$ & valor-p & $\begin{array}{c}\text { Hipótese } \\
\text { aceita }\end{array}$ & $\mathrm{F}$ & valor-p & $\begin{array}{c}\text { Hipótese } \\
\text { aceita }\end{array}$ \\
\hline $\mathrm{pH}$ & 2,96 & $3,88 \mathrm{E}-02$ & $\mathrm{H}_{1}$ & 54,23 & $4,26 \mathrm{E}-10$ & $\mathrm{H}_{1}$ & 1,84 & $1,50 \mathrm{E}-01$ & $\mathrm{H}_{0}$ \\
\hline Temper. & 0,51 & 0,67 & $\mathrm{H}_{0}$ & 39,62 & $3,16 \mathrm{E}-08$ & $\mathrm{H}_{1}$ & 4,84 & 0,004 & $\mathrm{H}_{1}$ \\
\hline Cloreto & 0,49 & $7,83 \mathrm{E}-01$ & $\mathrm{H}_{0}$ & 1,44 & $2,89 \mathrm{E}-01$ & $\mathrm{H}_{0}$ & 10,71 & $1,52 \mathrm{E}-05$ & $\mathrm{H}_{1}$ \\
\hline $\mathrm{CE}$ & 12,99 & $1,001 \mathrm{E}-06$ & $\mathrm{H}_{1}$ & 51,97 & $7,999 \mathrm{E}-10$ & $\mathrm{H}_{1}$ & 14,51 & $2,57 \mathrm{E}-07$ & $\mathrm{H}_{1}$ \\
\hline STD & 14,92 & $1,80 \mathrm{E}-07$ & $\mathrm{H}_{1}$ & 105,74 & $3,47 \mathrm{E}-15$ & $\mathrm{H}_{1}$ & 18,21 & $1,18 \mathrm{E}-08$ & $\mathrm{H}_{1}$ \\
\hline Cor & 70,03 & $3,46 \mathrm{E}-20$ & $\mathrm{H}_{1}$ & 248,96 & $9,71 \mathrm{E}-24$ & $\mathrm{H}_{1}$ & 49,45 & $1,17 \mathrm{E}-16$ & $\mathrm{H}_{1}$ \\
\hline $\mathrm{Na}$ & 9,69 & 2,32E-05 & $\mathrm{H}_{1}$ & 8,06 & 0,006 & $\mathrm{H}_{1}$ & 9,79 & $2,1 \mathrm{E}-05$ & $\mathrm{H}_{1}$ \\
\hline K & 6,31 & $8,07 \mathrm{E}-04$ & $\mathrm{H}_{1}$ & 23,43 & $8,52 \mathrm{E}-06$ & $\mathrm{H}_{1}$ & 3,41 & $2,26 \mathrm{E}-02$ & $\mathrm{H}_{1}$ \\
\hline Alcal. & 3,75 & $1,52 \mathrm{E}-02$ & $\mathrm{H}_{1}$ & 2,23 & $1,40 \mathrm{E}-01$ & $\mathrm{H}_{0}$ & 3,01 & $3,66 \mathrm{E}-02$ & $\mathrm{H}_{1}$ \\
\hline Dureza & 5,66 & $1,67 \mathrm{E}-03$ & $\mathrm{H}_{1}$ & 121,25 & $2,07 \mathrm{E}-16$ & $\mathrm{H}_{1}$ & 4,44 & $6,77 \mathrm{E}-03$ & $\mathrm{H}_{1}$ \\
\hline Cálcio & 1,49 & $2,27 \mathrm{E}-1$ & $\mathrm{H}_{0}$ & 235,84 & $3,85 \mathrm{E}-23$ & $\mathrm{H}_{1}$ & 4,27 & $8,23 \mathrm{E}-3$ & . \\
\hline
\end{tabular}

Nota: hipóteses nulas: Ho1 - não há efeito pela sazonalidade (duas campanhas de coleta), Ho2- não há efeito entre os quatro pontos de amostragem e Ho3 - não há combinação entre os efeitos sazonalidade e pontos de amostragem. Hipóteses alternativas: $\mathrm{H}_{1}$ - há efeito em cada um dos três casos.

Os sólidos totais dissolvidos (STD) estão relacionados diretamente com a condutividade elétrica (Araújo e Oliveira, 2013; Esteves, 2011, 1998; Tundisie e Matsumura Tundisi, 2008) e é usada em laboratório de rotina como medida da salinidade da água e/ ou dos efeitos causados por alguma atividade antrópica que afete um corpo d'água (Van Niekerk et al., 2014). Os STD, ao serem relacionados com a condutividade elétrica e quando não podem ser medidos, é usado um fator de conversão como no estudo realizado por Frančišković-Bilinski, et al. (2013) que multiplicou por 0,67 e desta forma calculou os STD das nascentes que estudaram. Os teores médios dos STD no estudo são resumidos na Tabela 1 , com valores de 16,28 a 27,05 mg L $\mathrm{m}^{-1}$ para o período menos chuvoso e de 10,38 a $13,35 \mathrm{mg} \mathrm{L}^{-1}$ no período chuvoso. Em águas continentais, os STD variam em relação à hidrogeoquímica regional e das drenagens de rochas ígneas ou sedimentares (Tundisi e Matsumura Tundisi, 2008). Os STD incluem todos os sais e componentes não iônicos. Os processos de intemperismo geram produtos que são encontrados nos corpos da água na forma iônica, que são os principais constituintes dos STD. Este parâmetro é utilizado no controle de poluição de corpos d'água natural com esgotos sanitários e efluentes industriais, para avaliar a eficiência nas estações de tratamentos de efluentes como Marimuthu et al. (2013) em Tamilnadu na Índia. Os resultados obtidos mostram que o ponto P-02 no período menos chuvoso tem o teor mais elevado de STD (Figura 2(d)), deduzindo que as atividades industriais da área estão impactando os corpos receptores. Os teores médios de STD obtidos no presente estudo foram menores a $500 \mathrm{mg} \mathrm{L}^{-1}$, padrão de qualidade da resolução CONAMA 357 para águas doces classe I, II e III (CONAMA, 2005). Em um estudo de Barreto et al. (2014), foram medidos os teores de STD e avaliada a relação entre a vazão e a qualidade da água numa seção do Rio Catolé Grande-BA, onde observou-se um aumento dos STD ao aumentar a vazão do rio. A cor é uma característica física da água devido à existência de substâncias dissolvidas, ou em estado coloidal, na maioria dos casos de natureza orgânica (NBR 9896/1993). A cor é um parâmetro a ser avaliado segundo a legislação, em estudos da qualidade da água para potabilidade (Santos et al., 2015). Os valores médios obtidos da cor

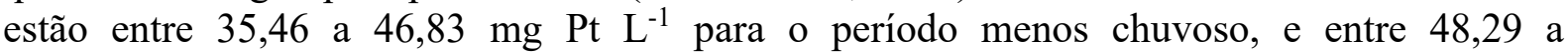
$96,11 \mathrm{mg} \mathrm{Pt} \mathrm{L}^{-1}$ para o período chuvoso (Tabela 1). Estatisticamente, a sazonalidade, a localização dos pontos de amostragem e a interação entre os dois fatores têm influência significativa no valor médio da cor rejeitando as hipóteses nulas (Tabela 2). Com o aumento das chuvas, aumenta o transporte de material orgânico e inorgânico drenado nas margens dos 
rios, o que influência um aumento na cor. As ligninas, taninos, substâncias húmicas e fúlvicas, algas e entre outras, provenientes da decomposição de material orgânico, principalmente de origem vegetal, são causadoras da cor em águas naturais (CETESB, 2012; León, 2005). Além disso, estas substâncias podem estar em solução originando a cor verdadeira ou em suspensão originando a cor aparente (USEPA, 2015; León, 2005; Esteves, 1998). Na Figura 2 (e) pode ser observado que os maiores teores correspondem à época mais chuvosa. Segundo Von Sperling (2007), as atividades antrópicas influem na constituição da cor na água pelo lançamento de efluentes domésticos e/ou industriais nos corpos d'agua, e de acordo com Skoronski et al., (2014) é um parâmetro indicador na avaliação da eficiência dos processos nas estações de tratamento de efluente. Segundo a CETESB, o esgoto doméstico se caracteriza por apresentar matéria orgânica coloidal. Outros constituintes de origem natural que causam a coloração na água são minerais dissolvidos como o ferro e manganês relacionados com a geologia dos solos das margens dos rios (CETESB, 2012; Von Sperling, 2007; León, 2005).
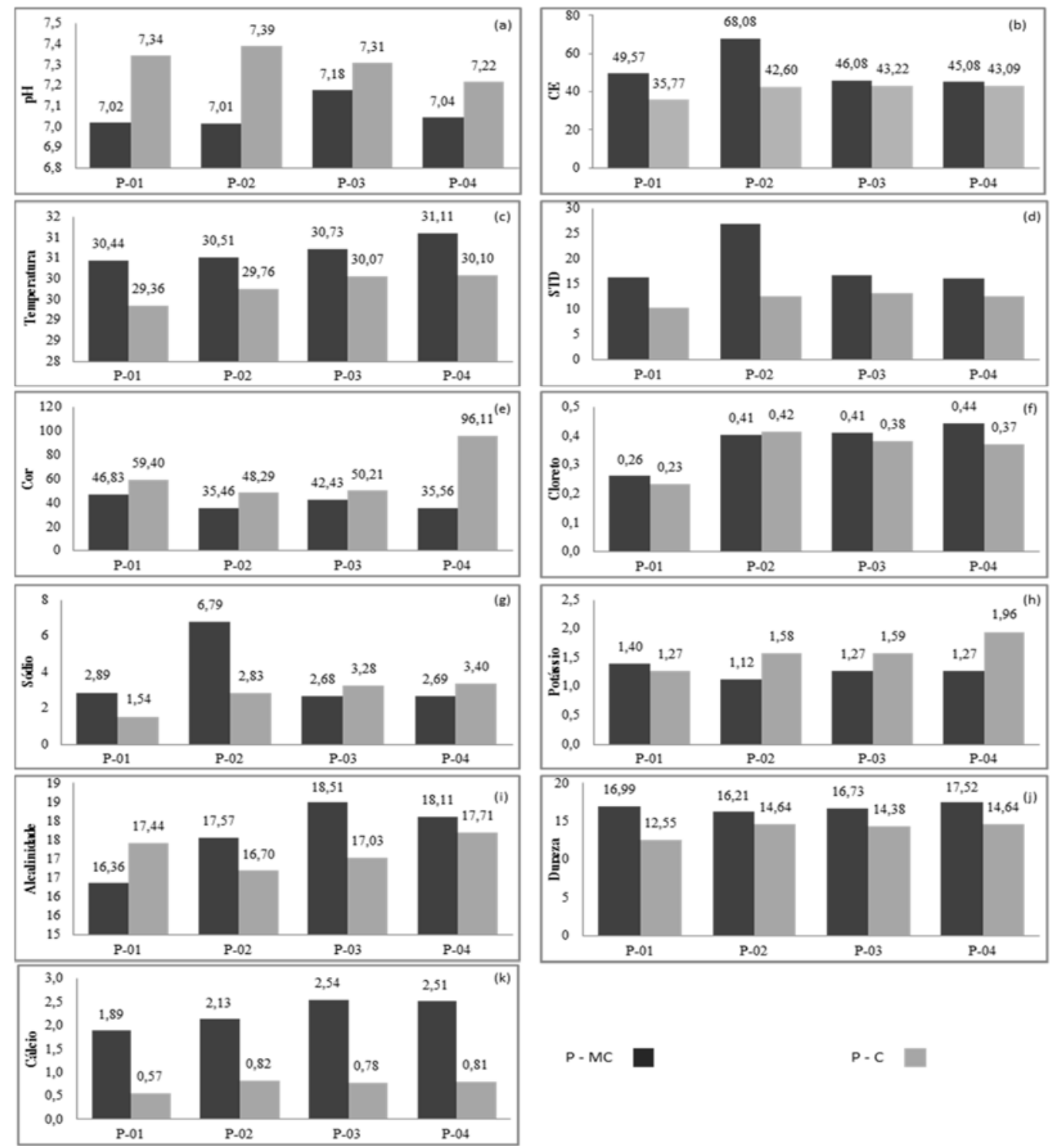

Figura 2. Distribuição dos teores médios dos parâmetros analisados: (a)pH, (b) Condutividade elétrica (CE) $\mu \mathrm{S} . \mathrm{cm}^{-1}$, (c) Temperatura ${ }^{\circ}$ C, (d) STD $\mathrm{mg} \mathrm{L}^{-1}$, (e) Cor, (f) Cloreto $m g \mathrm{~L}^{-1}$, (g) Sódio $\mathrm{m} \mathrm{L}^{-1}$, (h) Potássio $\mathrm{mg} \mathrm{L}^{-1}$, (i) Alcalinidade $m g \mathrm{~L}^{-1}$, (j) Dureza $\mathrm{mg} \mathrm{L}^{-1}$, (k) Cálcio $\mathrm{mg} \mathrm{L}^{-1}$. Ponto 1 (P-01), Ponto 2 (P-02), Ponto 3 (P-03), Ponto 4 (P-04), Período menos chuvoso (P- MC), Período chuvoso (P- C). 
O padrão estabelecido na resolução CONAMA 357 (2005) para a cor é de até $75 \mathrm{mg} \mathrm{Pt} \mathrm{L}{ }^{-1}$. Na Figura 2 (e) pode ser observado que no período menos chuvoso os quatro pontos de coleta estão dentro do padrão, porém no período chuvoso o ponto P-04 ultrapassa este limite (Tabela 1). Isto pode ser devido às atividades antrópicas realizadas nas margens do corpo hídrico em conjunto com o aumento da descarga hídrica. No trabalho Fonseca e Salvador (2005), também encontraram uma relação no aumento das unidades de cor no período de chuva, se comparado com o período menos chuvoso na Bacia hidrográfica do Rio Bonito- SP. A presença da cor na água nem sempre representa risco à saúde, mas a população pode questionar a qualidade da água (CETESB, 2012). O trabalho de Fonseca e Salvador (2005) mostra uma relação no aumento das unidades de cor no período de chuva, se comparado com o período menos chuvoso na Bacia hidrográfica do Rio Bonito- SP. Soares et al. (2009) obtiveram valores da cor fora dos padrões estabelecidos pelo CONAMA 357 (2005) em um estudo realizado no rio Águas Claras em Alvorada - RO, os quais estavam entre a faixa de 160 a $250 \mathrm{mg} \mathrm{Pt} \mathrm{L}{ }^{-1}$. Na caracterização de parâmetros do manancial Utinga na cidade de Belém-PA, Vasconcelos e Souza (2011) encontraram valores médios mensais nos anos 2007, 2008 e 2009 da cor de 53,89, 74,12 e 74,12 mg Pt L ${ }^{-1}$ respectivamente. Ainda que estes valores médios estejam enquadrados nos padrões legalmente permitidos, foi observado um aumento dos valores de um ano para o outro, o qual pode ser relacionado a um aumento das atividades antrópicas na região.

O cloreto é um íon importante nas águas subterrâneas e superficiais, podendo ter origem antrópica e geológica, sendo a lixiviação de rochas, esgotos domésticos e industriais a sua principal origem (USEPA, 2015). Segundo a CETESB (2012), uma pessoa expele na urina aproximadamente $4 \mathrm{~g}$ de cloreto por dia. O cloreto é um íon importante na produtividade global dos ecossistemas aquáticos, faz parte de importantes processos fisiológicos como a troca e/o transporte de outros íons para os meios intracelular e extracelular. Os teores médios da concentração de cloreto no período menos chuvoso foram de 0,26 a $0,44 \mathrm{mg} \mathrm{L}^{-1}$, e no período chuvoso está entre 0,23 e $0,42 \mathrm{mg} \mathrm{L}^{-1}$ (Tabela 1). Segundo o teste estatístico ANOVA (Tabela 2), não existiu evidência significativa de que a sazonalidade tenha um efeito na média dos valores aceitando a hipótese nula. A localização dos pontos de amostragem apresenta diferenças significativas no teor médio do cloreto aceitando a hipótese alternativa. Isto possivelmente se dá pelo lançamento de efluentes industriais, já que como descreve a CETESB (2012) e Von Sperling (2007), os efluentes também aportam quantidades consideráveis de cloreto dependendo do tipo de beneficiamento industrial. Na Figura 2 (f) pode ser observado que o ponto P-01 tem os valores médios mais baixos nas duas coletas. A interação dos dois fatores não tem efeito significativo nos teores médios do cloreto. Os teores de cloreto em ecossistemas continentais são extremamente variáveis. Em águas naturais, o teor do íon cloreto é menor que $50 \mathrm{mg} \mathrm{L}^{-1}$ (Rodier, 1981), e podem ser afetados pela entrada da pluma das correntes marinhas nos corpos de águas costeiras (Esteves, 2011; Hem, 1970), que podem conferir um sabor salgado à água ou propriedades laxativas (Lucas et al., 2014). Dados de Sioli (1984) mostram concentrações médias de cloreto dos rios Solimões, Negro e Tarumã-Mirim de $3,1 \mathrm{mg} \mathrm{L}^{-1} 1,7 \mathrm{mg} \mathrm{L}^{-1}$ e de 1,8 $\mathrm{mg} \mathrm{L}^{-1}$, respectivamente; Siqueira et al. (2012) em um diagnóstico do Rio Parauapebas- PA, encontraram teores de $0,40 \mathrm{mg} \mathrm{L}^{-1}$ de $\mathrm{Cl}^{-}$demonstrando que as concentrações baixas são comuns nos rios Amazônicos. A média mundial das concentrações de cloreto é de $7,8 \mathrm{mg} \mathrm{L}^{-1}$ (Esteves, 2011). Estudos em outras regiões encontraram concentrações de cloreto de 4,43 a 299,26 $\mathrm{mg} \mathrm{L}^{-1} \mathrm{Cl}^{-}$(Lucas et al., 2014) no Riacho Jacaré em Sergipe, e em uma avaliação da qualidade sazonal das águas, Ribeiro et al. (2013) em função ao lançamento de efluentes de abate bovino, reportaram teores de 0,08 a $1,84 \mathrm{mg} \mathrm{L}^{-1} \mathrm{Cl}^{-}$no período seco e de 0,34 a $1,39 \mathrm{mg} \mathrm{L}^{-1} \mathrm{Cl}^{-}$no período chuvoso; Souza et al. (2015) reportaram teores de 19,3 a 35,4 $\mathrm{mg} \mathrm{L}^{-1} \mathrm{Cl}^{-}$. Desta forma observa-se que diversos fatores afetam a concentração de cloreto nos corpos d'água. Nos padrões de enquadramento das águas doces no CONAMA 357, o valor máximo permitido de cloreto é de $250 \mathrm{mg} \mathrm{L}^{-1}$ para águas 
doces classe I, II e III, e os resultados obtidos neste estudo se enquadram nesta normativa (CONAMA, 2005). Contudo, em caracterizações gerais de recursos hídricos, o cloreto é um componente encontrado naturalmente em análises de rotina (Alfaro, 2014).

O sódio é um dos elementos encontrado em maior abundância na Terra, sendo solúvel em água (Lucas et al., 2014). Segundo a USEPA (2015) o sódio pode entrar nos corpos d'água por fontes naturais ou antrópicas. No primeiro caso pode ser por lixiviação das rochas e no segundo caso por esgotos sanitários, efluentes industriais e/ou atividades agrícolas (CETESB, 2012; Von Sperling, 2007). As concentrações de sódio obtidas no estudo no período menos chuvoso compreende teores médios de 2,68 a $6,79 \mathrm{mg} \mathrm{L}^{-1}$, e no período chuvoso estão entre 1,54 e $3,40 \mathrm{mg} \mathrm{L}^{-1}$ (Tabela 1). A sazonalidade, a localização dos pontos de amostragem e a interação entre os dois fatores têm influência significativa nos teores médios do sódio rejeitando as hipóteses nulas nos três casos. Nos ecossistemas aquáticos costeiros, o aumento na concentração de sódio pode ser influenciado pela entrada de águas marinhas (CETESB, 2012; Esteves, 2011; Tundisi e Matsumura Tundisi, 2008; Rodier, 1981). Segundo a CETESB (2012), as concentrações de sódio em águas superficiais variam consideravelmente por fatores como a geologia do local, as descargas de efluentes, o uso sazonal de sais nas rodovias e o uso de fertilizantes na agricultura. De acordo com Fittkau et al. (1975), a média do sódio do Rio Amazonas varia entre 1,15 a 2,90 $\mathrm{mg} \mathrm{L}^{-1}$. No estudo de Ribeiro et al. (2013) no ponto de amostragem com influência de lançamento de efluentes de abate bovino encontraram concentrações de sódio de 14,52 a 197,5 $\mathrm{mg} \mathrm{L}^{-1}$ para o período seco, e de 11,33 a 189,38 mg L-1 no período chuvoso, sendo que as maiores concentrações foram encontradas na jusante do córrego, apontando um comportamento similar, com concentração do sódio com menores teores obtidos no período chuvoso.

Pode ser observado na Figura 2 (g) que os teores médios mais elevados correspondem ao período menos chuvoso, possivelmente pela influência de correntes oceânicas no trecho do rio estudado. Entretanto, o ponto P-02 apresentou o teor de sódio mais elevado no período seco, devido provavelmente a impactos ambientais do local. Segundo a CETESB (2012), os valores podem estender-se de $1 \mathrm{mg} \mathrm{L}^{-1}$ ou menos, até $10 \mathrm{mg} \mathrm{L}^{-1}$. Muitas águas superficiais incluindo aquelas que recebem efluentes têm níveis bem abaixo de $50 \mathrm{mg} \mathrm{L}^{-1}$.

O potássio é um elemento que está em baixas concentrações nas águas naturais, sendo a lixiviação das rochas a sua principal fonte natural. Portanto, a fonte antrópica é uma das suas fontes, visto que é um elemento utilizado na indústria e na agricultura (Zuin et al., 2009). Uma importante função do potássio é a troca e transporte de outros íons para os meios intracelular e extracelular (Esteves, 2011). Os resultados do presente estudo mostraram que a concentrações médias de potássio obtidas foram de 1,27 a $1,96 \mathrm{mg} \mathrm{L}^{-1}$ para o período chuvoso, e,de 1,12 a $1,40 \mathrm{mg} \mathrm{L}^{-1}$ para o período menos chuvoso (Tabela 1). Estes teores encontrados foram maiores se comparados com valores obtidos por Ferch (1984) no Rio Solimões (valores de 0,9 $\mathrm{mg} \mathrm{L}^{-1}$ ) e no rio Negro $\left(0,3 \mathrm{mg} \mathrm{L}^{-1}\right)$. No entanto, o mesmo autor estudou o lago Camaleão, localizado no interior da ilha da Marchantaria no rio Solimões (AM), e observaram alterações na concentração do potássio em função da variação do nível de água. No período de águas baixas, a concentração foi aproximadamente 15 vezes o valor obtido no rio Solimões, já que na enchente o rio invade as águas do lago efetuando uma diluição, refletindo na redução de concentração de potássio. Na Figura 2 (h) pode ser observado que os maiores valores correspondem à época chuvosa. Estatisticamente, a sazonalidade da localização dos pontos de amostragem e a interação destes fatores têm influência significativa nos teores médios do potássio rejeitando as hipóteses nulas (Tabela 2). Com relação à localização dos pontos de amostragem, deve-se ter em conta que as concentrações elevadas de potássio são principalmente encontradas em águas residuais (Monaco, 2011). De acordo com Alfaro (2014), o potássio é dos poucos compostos encontrados naturalmente em corpos d'água. Está

Rev. Ambient. Água vol. 12 n. 3 Taubaté - May / Jun. 2017 
distribuído amplamente no ambiente. Desta forma, as concentrações de água bruta e potável de diferentes partes do Canadá variam de $<1$ a $8 \mathrm{mg} \mathrm{L}^{-1}$. Entretanto na Província de Saskatchewan as concentrações estão acima de $51 \mathrm{mg} \mathrm{L}^{-1}$, onde possui um dos maiores depósitos de potássio do mundo (CETESB, 2012). Segundo Esteves (2011), as concentrações médias de potássio em rios de América do Sul são de $2 \mathrm{mg} \mathrm{L}^{-1}$.

A alcalinidade nas águas naturais, responsável pela capacidade de neutralização de ácidos, geralmente apresenta como principais responsáveis: bases conjugadas de ácido carbônico, carbonatos e bicarbonatos; outras bases derivadas do íon amônio e dos ácidos sulfúrico e fosfórico também podem contribuir para a alcalinidade (Esteves, 2011; Hem, 1970). Os teores médios da alcalinidade no período menos chuvoso foram de 16,36 a $18,51 \mathrm{mg} \mathrm{L}^{-1}$ de $\mathrm{CaCO}_{3}$, e

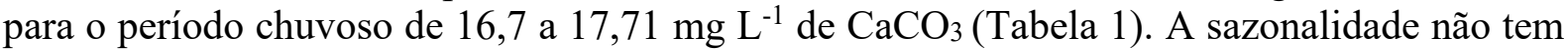
influência significativa no valor médio da alcalinidade (Tabela 2), embora para os fatores da localização dos pontos de amostragem e sua interação com a sazonalidade, observou-se evidência significativa para afirmar que eles afetam os teores médios da alcalinidade. Pode ser observado na Figura 2 (i), com exceção do ponto P-01, a alcalinidade foi maior para o período menos chuvoso. A alcalinidade não tem um significado sanitário, com exceção de quando ela ocorre devido a hidróxidos, ou quando contribua na qualidade de sólidos totais. Segundo a Secretaria de Vigilância em Saúde (Brasil, 2006), a maioria das águas naturais apresenta valores de alcalinidade na faixa de 30 a $500 \mathrm{mg} \mathrm{L}^{-1}$ de $\mathrm{CaCO}_{3}$. No presente estudo os valores são inferiores, e característicos de rios amazônicos.

A dureza é a concentração de cátions multimetálicos em solução. Os cátions frequentemente associados à dureza são cálcio e magnésio $\left(\mathrm{Ca}^{2+}, \mathrm{Mg}^{2+}\right)$, e em menor escala ferro $\left(\mathrm{Fe}^{2+}\right)$, manganês $\left(\mathrm{Mn}^{2+}\right)$, estrôncio $\left(\mathrm{Sr}^{2+}\right)$ e alumínio $\left(\mathrm{Al}^{3+}\right)$ (USEPA, 2015; Brasil, 2006). Segundo a UNEP (2008) a dureza é influenciada pela geologia da bacia de drenagem e por atividades antrópicas. As principais fontes de dureza são a dissolução de minerais contendo cálcio e magnésio, exemplificando, as rochas calcárias e os despejos industriais (Von Sperling, 2007). Os valores da dureza mudaram entre 16,21 e $17,52 \mathrm{mg} \mathrm{L}^{-1}$ de $\mathrm{CaCO}_{3}$ para o período menos chuvoso e 12,55 a 12,64 $\mathrm{mg} \mathrm{L}^{-1}$ de $\mathrm{CaCO}_{3}$ para o período chuvoso, sendo menores para este período (figura $2(\mathrm{j})$ ). De acordo com o teste ANOVA, existe evidência significativa para afirmar que a sazonalidade, a distribuição dos pontos de coleta e a interação dos dois fatores afetam no teor médio da dureza rejeitando as hipóteses nulas (Tabela 2). Geralmente ambientes com $\mathrm{pH}$ próximos à neutralidade apresentam uma dureza mole dado pelas baixas concentrações de carbonatos, sendo a reação com o $\mathrm{CO}_{2}$ para a produção de bicarbonato desprezível (Esteves,

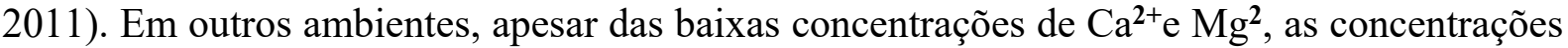
de $\mathrm{Na}_{2} \mathrm{CO}_{3}$ são consideráveis. Em outras palavras, estes ambientes com baixa dureza podem apresentar elevada alcalinidade. Os dados obtidos no presente estudo se mostraram correspondentes a águas moles de acordo com Mol e Alii (2005, apud Esteves (2011), que estabelece até $75 \mathrm{mg} \mathrm{L}^{-1}$ de $\mathrm{CaCO}_{3}$. De acordo com a legislação (Brasil, 2006) nos corpos d'água de reduzida dureza, a biota é mais sensível à presença de substâncias tóxicas, já que a toxicidade é inversamente proporcional ao grau de dureza da água, que tem efeito de reduzir a toxicidade de alguns metais como cobre, zinco, chumbo, etc. (USEPA, 2015). Os dados deste estudo apresentaram teores baixos de dureza se comparados com o estudo realizado por Paiva e Souza (2010) no rio Riachão em Caatiba- BA, que reportaram teores de 18,2 a 45,6 mg L $\mathrm{me}^{-1}$ de $\mathrm{CaCO}_{3}$.

De acordo com a UNEP (2008) a concentração média do cátion Ca em diferentes rios e lagos é de $13 \mathrm{mg} \mathrm{L}^{-1}$ na África, $22 \mathrm{mg} \mathrm{L}^{-1}$ nas Américas, $20 \mathrm{mg} \mathrm{L}^{-1}$ na Ásia, $45 \mathrm{mg} \mathrm{L}^{-1}$ na Europa e de $8 \mathrm{mg} \mathrm{L}^{-1}$ na Oceania. Nas águas naturais, o cálcio é o principal cátion, porém de acordo com Sioli (1956), em certas águas amazônicas pode ser muito escasso variando entre 1 a $4 \mathrm{mg} \mathrm{L}^{-1}$ de $\mathrm{Ca}$, valores baixos e dificilmente encontrados em outras regiões da Terra. Os valores médios obtidos para o período menos chuvoso estão entre 1,89 e $2,54 \mathrm{mg} \mathrm{L}^{-1}$ de Ca, e 
para o período chuvoso é de 0,57 a $0,81 \mathrm{mg} \mathrm{L}^{-1}$ de Ca. A composição iônica das águas varia em função das características do terreno, de áreas inundadas, presença da vegetação e uso dos solos ao longo do tempo (Tundisi e Matsumura Tundisi, 2008). Águas muito pouco mineralizadas com composição iônica dissolvida ocorrem em muitas regiões do Brasil. Na Figura 2 (k), pode ser observado que as menores concentrações de cálcio correspondem ao período chuvoso, o que concorda com Sioli (1956), que diz que o cálcio geralmente diminui com o aumento das chuvas. Estatisticamente, a sazonalidade e a localização dos pontos de amostragem influem significativamente nos teores médios do cálcio. Segundo Esteves (2011) e a UNEP (2008), o cálcio pode ter uma dinâmica sazonal e espacial relativamente marcada como resultado da atividade biológica. Em outro estudo, realizado por Kemerich et al. (2012) na caracterização química de água subterrânea numa área ocupada por cemitério em Santa Maria- RS reportaram teores de 4,65 a 17,85 $\mathrm{mg} \mathrm{L}^{-1}$ de Ca. Behera et al. (2014), ao estudarem o manguezal do rio Mahanadi na Índia, obtiveram valores elevados de teores de cálcio, de 125,4 a 400,8 $\mathrm{mg} \mathrm{L}^{-1}$, sendo atribuídos a efluentes de atividades industriais, comprovando, desta forma, sua dinâmica no meio ambiente.

\section{2. Índice de qualidade das águas (IQA)}

Com a aplicação da metodologia de cálculo de IQA para as amostragens consideradas neste estudo, foram determinados 40 diferentes resultados, que podem ser observados na Tabela 3.

Tabela 3. Resultados de IQA.

\begin{tabular}{lcccccccc}
\hline Período & Ponto & Long & Lat & $07 \mathrm{~h} 30$ & $10 \mathrm{~h} 30$ & $12 \mathrm{~h} 00$ & $13 \mathrm{~h} 30$ & $16 \mathrm{~h} 30$ \\
\hline \multirow{4}{*}{ PC } & P1 & 744945,8 & 9822509,3 & 56,576 & 90,998 & 57,649 & 56365 & 56,881 \\
& P2 & 747086,9 & 9826412,2 & 57,131 & 56,441 & 56,441 & 90,900 & 91,361 \\
& P3 & 748593,8 & 9829178,9 & 57,201 & 56,886 & 91,345 & 56,921 & 56,446 \\
& P4 & 754846,6 & 9835755,0 & 55,820 & 54,662 & 55,380 & 55,187 & 54,924 \\
\hline \multirow{4}{*}{ PMC } & P1 & 744945,8 & 9822509,3 & 85,575 & 75,593 & 89,932 & 88,535 & 83,385 \\
& P2 & 747086,9 & 9826412,2 & 86,818 & 55,042 & 86,837 & 91,329 & 88,277 \\
& P3 & 748593,8 & 9828178,9 & 79,305 & 88,954 & 88,871 & 91,394 & 88,724 \\
& P4 & 754846,6 & 9835755,0 & 92,013 & 89,671 & 86,734 & 91,550 & 91,676 \\
\hline
\end{tabular}

Interpretando tais resultados de acordo com o que recomenda a CETESB (2014), pode ser observado que durante o período chuvoso (PC), as águas estiveram, de modo geral, com qualidade inferior as águas do período menos chuvoso (PMC). Essa constatação pode ser facilmente observada na Tabela 4.

Tabela 4. Interpretações de IQA.

\begin{tabular}{ccccccccc}
\hline Período & Ponto & Long & Lat & 07h30 & $10 \mathrm{~h} 30$ & $12 \mathrm{~h} 00$ & $13 \mathrm{~h} 30$ & $16 \mathrm{~h} 30$ \\
\hline \multirow{4}{*}{ PC } & P1 & 744945,8 & 9822509,3 & Boa & Ótima & Boa & Boa & Boa \\
& P2 & 747086,9 & 9826412,2 & Boa & Boa & Boa & Ótima & Ótima \\
& P3 & 748593,8 & 9829178,9 & Boa & Boa & Boa & Boa & Boa \\
& P4 & 754846,6 & 9835755,0 & Boa & Boa & Boa & Boa & Boa \\
\hline \multirow{4}{*}{ PMC } & P1 & 744945,8 & 9822509,3 & Ótima & Boa & Ótima & Ótima & Ótima \\
& P2 & 747086,9 & 9826412,2 & Ótima & Boa & Ótima & Ótima & Ótima \\
& P3 & 748593,8 & 9828178,9 & Ótima & Ótima & Ótima & Ótima & Ótima \\
& P4 & 754846,6 & 9835755,0 & Ótima & Ótima & Ótima & Ótima & Ótima \\
\hline
\end{tabular}

Rev. Ambient. Água vol. 12 n. 3 Taubaté - May / Jun. 2017 
Tal diferença pode ser explicada pela sazonalidade, uma vez que maiores níveis pluviométricos implicam em maiores teores de poluentes, sendo carreados pela chuva do solo em direção ao rio - fenômeno chamado de wash off (Dotto, 2006). Tratando-se, então, de uma área que sofre intensa pressão antrópica - seja pelo lançamento direto de efluentes no solo, ou pela disposição inadequada de rejeitos domésticos e industriais. Admite-se que os menores valores de IQA durante a amostragem PC estão intrinsecamente ligados à maior quantidade de chuvas.

Dois parâmetros foram determinantes na redução dos valores de IQA para o PC: turbidez e coliformes. O parâmetro turbidez, apesar de indicativo de possível contaminação por patógenos, não representa sozinho indicativo de água de qualidade inferior. A turbidez é, no contexto amazônico, lugar comum nas caracterizações de águas brutas por conta do elevado teor de sedimentos que estas transportam (Filizola et al., 1999).

Estabelecendo uma conexão entre os valores de turbidez e as análises de coliformes termotolerantes, que indicaram altos teores de microrganismos, é possível afirmar que as altas taxas de turbidez podem estar relacionadas também, ao lançamento inadequado de efluentes frescos ou mais concentrados no rio (Von Sperling, 2005).

Esses dois parâmetros juntos podem indicar contaminação de águas por patógenos uma vez que: 1) as partículas em suspensão que contribuem para o aumento da turbidez podem servir como meio para a proliferação de bactérias (Von Sperling, 2005); 2) a presença de microrganismos que só se desenvolvem no intestino de animais quentes indica a presença de carga orgânica proveniente de efluentes domésticos (CB6).

Além de efluentes das atividades nativas do município de Barcarena-PA, a zona portuária alvo de estudo pode estar recebendo efluentes provenientes dos navios que ali transitam diariamente. Além de efluentes domésticos, estes navios podem estar despejando águas de lastro de outros ecossistemas, alterando não só as características físico-químicas da água, mas também sua composição de fauna e flora nas escalas macro e micro (Serafin e Henkes, 2013).

A inferioridade dos valores de IQA de PC em relação a PMC não implica, no entanto, em águas de qualidade insatisfatória. Rios de dimensões como o Rio Pará e que sofrem influência direta de maré oceânica, tem grande capacidade de diluição de seus poluentes. Damasceno et al. (2015), ao estudarem um ciclo sazonal de um trecho do rio Amazonas, no município de Macapá, obtiveram IQA com classificações de boa e ótima. Em outro estudo realizado por Alves et al. (2012) no rio Arari no Marajó- PA, foi obtido uma classificação de IQA entre ruim e regular, e estes mesmos resultados foram obtidos por Lobato et al. (2015) em um estudo realizado no lago Tucuruí- PA.

\section{CONCLUSÃO}

Dos parâmetros analisados, com exceção do $\mathrm{pH}$, estatisticamente o fator localização dos pontos de amostragem tem uma influência significativa nos valores médios da temperatura, condutividade, cor, sólidos totais dissolvidos, cloreto, sódio, potássio, alcalinidade, dureza e cálcio com um nível de significância de 5\%. Tais interferências se devem a hidrodinâmica do corpo hídrico pela interferência da entrada e saída de correntes oceânicas, produto da maré, e por outro lado a recepção de efluentes domésticos e industriais.

A condutividade, STD e sódio foram os parâmetros que apresentaram uma maior concentração no ponto P-02 que recebe a maior influência das atividades das empresas localizadas no pólo industrial de Barcarena-PA, parâmetros estes relacionados com lançamento de efluentes industriais e esgoto doméstico.

Segundo o teste ANOVA, a sazonalidade tem influência significativa nos teores médios dos parâmetros de $\mathrm{pH}$, temperatura, condutividade, $\mathrm{STD}$, cor, sódio, potássio, dureza e cálcio. 
Porém, não tem influência no cloreto e alcalinidade, pois com o aumento das chuvas alguns parâmetros da qualidade das águas podem ser afetados.

A interação da sazonalidade e localização dos pontos de amostragem têm influência significativa no $\mathrm{pH}$, condutividade, $\mathrm{STD}$, cor, sódio, potássio, dureza e alcalinidade, mas não têm influência no cálcio, cloreto e temperatura.

Os parâmetros analisados neste estudo mostraram valores dentro do padrão de qualidade da resolução CONAMA 357/2005, com exceção da cor no ponto P0-4 no período chuvoso.

Os Índices de Qualidade da água se mostraram satisfatórios, com aproximadamente metade das amostras caracterizadas com índice bom, e as demais caracterizadas com IQA ótima. Estes índices refletem a capacidade de diluição de poluentes que um rio do porte do Rio Pará tem, este fenômeno potencializado pelo efeito de marés oceânicas no corpo hídrico estudado.

Apesar dos índices satisfatórios retratados pelo IQA, as amostras apresentaram considerável presença de coliformes termotolerantes.

\section{AGRADECIMENTOS}

Ao Programa de Pós-Graduação em Ciências Ambientais (PPGCA) da Universidade do Estado do Pará (UEPA). À Coordenação de Aperfeiçoamento de Pessoal de Nível Superior (CAPES), pela bolsa de estudo. Ao projeto Qualidade dos Recursos Hídricos para o consumo humano na área de abrangência do Polo Industrial de Barcarena Pará da FAPESPA, edital $013 / 2009$, pelo financiamento para as coletas e análises.

\section{REFERÊNCIAS}

ASSOCIAÇÃO BRASILEIRA DE NORMAS TÉCNICAS. NRB 9898 - Preservação e técnicas de amostragem de efluentes líquidos e corpos receptores. Rio de Janeiro, 1987.

ALFARO, J. D. B. Determinación de cationes en agua potable del cantón de Grecia, Costa Rica por absorción atómica. Revista. InterSedes, v 15, p. 95-106, 2014. http://repositoriodigital.academica.mx/jspui/handle/987654321/402610

ALVARENGA, L. A. et al. Estudo da qualidade e quantidade da água em microbacia, afluente do rio Paraíba do Sul - São Paulo, após ações de preservação ambiental. Revista Ambiente \& Água, v. 7, n. 3, p. 228-240, 2012. http://dx.doi.org/10.4136/ambi-agua.987

ALVES, I. C. C.; El-ROBRINI, M.; SANTOS, M. de L. S. MONTEIRO S. M.; BARBOSA, L. P. F.; GUIMARÃES, J. T. F. Qualidade das águas superficiais e avaliação do estado trófico do Rio Arari (Ilha de Marajó, norte do Brasil). Acta Amazonica, v. 42, n. 1, p. 115-124, 2012. http://dx.doi.org/10.1590/S0044-59672012000100014

ARAUJO, M. C. de; OLIVEIRA, M. B M. de. Monitoramento da qualidade das águas de um riacho da Universidade Federal de Pernambuco, Brasil. Revista Ambiente \& Água, v. 8, n. 3, p. 247-257, 2013. http://dx.doi.org/10.4136/ambi-agua.1192

AMERICAN PUBLIC HEALTH ASSOCIATION et al. Standard methods for the examination of water and wastewater. $19^{\text {th }}$ ed. Washington, 1995. $1134 \mathrm{p}$. 
BARRETO, L. V.; FRAGA, M. S.; BARROS, F. M.; ROCHA, F. A.; AMORIM, J. S.; DE CARVALHO, S. R. et al. Relação entre vazão e qualidade da água em uma seção de rio. Revista Ambiente \& Água, v. 9, p. 118-129, 2014. http://dx.doi.org/10.4136/ambiagua. 1278

BEHERA B. C.; MISHRA R. R.; PATRA J. K.; DUTTA S. K.; THATOI, H. N. Physico chemical properties of water sample collected from Mangrove Ecosystem of Mahanadi river delta, Odisha, India. American Journal of Marine Science, v. 2, n. 1, p. 19-24, 2014. http://dx.doi.org/10.12691/marine-2-1-3

BOESCH, D. F. Challenges and opportunities for science in reducing nutrient over-enrichment of coastal ecosystems. Estuaries, v. 25, n. 4b, p. 886-900, 2002. http://dx.doi.org/10.1007/BF02804914

BRASIL. Secretaria de Vigilância em Saúde. Vigilância e controle da qualidade da água para o consumo. Brasília, 2006. 212 p.

BUCCI, M. H. S.; OLIVEIRA, L. F. C. Índices de qualidade da água e de estado trófico na represa Dr. João Penido (Juiz de Fora, MG). Revista Ambiente \& Água, v. 9, n. 1, p. 130-148, 2014. http://dx.doi.org/10.4136/ambi-agua.1290

BUCCI, M. M. H. S.; DELGADO, F. E. F. da; SANTOS, D. da S.; OLIVEIRA, L. F C.de. Análise de metais, agrotóxicos, parâmetros físico-químicos e microbiológicos nas águas da Represa Dr. João Penido, Juiz de Fora, MG. Revista Ambiente \& Água, v. 10, n. 4, p. 804-824, 2015. http://dx.doi.org/10.4136/ambi-agua.1534

CARREÓN, E. T.; SEDENO J. E. D.; LOPEZ E. L. Evaluación de la calidad del agua en la Laguna de Yuriria, Guanajuato, México, mediante técnicas multivariadas: un análisis de valoración para dos épocas 2005, 2009-2010. Revista Internacional Contaminación Ambiental, v. 29, n. 3, p. 147-163, 2013.

COMPANHIA AMBIENTAL DO ESTADO DE SÃO PAULO. IQA: Índice de qualidade das águas. Disponível em: http://www.cetesb.sp.gov.br/agua/ÁguasSuperficiais/42-Índicede-Qualidade-dasÁguas-(iqa). Acesso em: 28 set. 2014.

COMPANHIA AMBIENTAL DO ESTADO DE SÃO PAULO. Website. 2012. http://www.cetesb.sp.gov.br. Acesso: 20 set. 2012.

CHAN SANTISTEBAN, M. L.; PENA, W. Evaluación de la calidad del agua superficial con potencial para consumo humano en la cuenca alta del SisIcán, Guatemala. Cuadernos de Investigación UNED, v. 7, n. 1, p. 19-23, 2015.

COHEN, J. C. P.; BELTRAO, J. da C.; GANDU, A. W.; SILVA, R. R. da. Influência do desmatamento sobre o ciclo hidrológico na Amazônia. Ciência e Cultura, v. 59, n. 3, p. 36-39, 2007.

COMPANHIA DOCAS DO PARÁ - CDP. Atualização do plano de desenvolvimento e zoneamento do porto de Vila do Conde. Belém, 2010.

CONSELHO NACIONAL DO MEIO AMBIENTE. Resolução No 430, de 13 de Maio de 2011. Dispõe sobre as condições e padrões de lançamento de efluentes, complementa e altera a Resolução no 357, de 17 de março de 2005, do Conselho Nacional do Meio AmbienteCONAMA. Diário Oficial [da] União, n. 92, 16 maio 2011, p. 89. Brasilia, 2011. 
CONSELHO NACIONAL DO MEIO AMBIENTE. Resolução n 357, de 17 de março de 2005. Dispõe sobre a classificação dos corpos de água e diretrizes ambientais para o seu enquadramento, bem como estabelece as condições e padrões de lançamento de efluentes, e dá outras providências. Diário Oficial [da] União, n. 53, 18 mar. 2005, p. 58-63.

DAMASCENO, M. da C. S.; RIBEIRO, H. M. C.; TAKIYAMA, L. R.; PAULA, M. T. de. Avaliação sazonal da qualidade das águas superficiais do Rio Amazonas na orla da cidade de Macapá, Amapá, Brasil. Revista Ambiente \& Água, v. 10, n. 3, p. 598-613, 2015. http://dx.doi.org/10.4136/ambi-agua.1606

DOTTO, C. B. S.; PAIVA, E. M. C. D.; SILVA, L. F. Acumulação e balanço de sedimentos em superfícies asfálticas em área urbana de Santa Maria - RS. Revista Brasileira de Recursos Hidrícos, v. 12, p. 1-11, 2006.

DREVER, J. I. The Geochemistry of natural waters. [S.1.]: Prentice Hall, 1988.

EMPRESA BRASILEIRA DE PESQUISA AGROPECUÁRIA. Centro Nacional de Pesquisa de Solos. Sistema brasileiro de classificação de solos. Brasília, 2013. 306p.

ESTEVES, F. Fundamentos de limnologia, Rio de Janeiro: Interciência, 1998. 601 p.

ESTEVES, F. Fundamentos de limnologia. 3. ed. Rio de Janeiro: Interciência, 2011. 826 p.

FILIZOLA, N.; GUYOT, J. L.; BOAVENTURA, G. Fluxo de sedimentos em suspensão na Amazônia-uma análise a partir da base de dados da ANEEL. 1999. Disponível em: http://www.ana.gov.br/hibam/publicacoes/filizola_1.pdf.

FITTKAU, E. J.; JUNK, W.; KLINGE, H.; SIOLI, H. Substrate and vegetation in the Amazon region. In: CRAMER, J. (Ed.). Beriohto dor internationalen Symposien der Internationalen Vereinigung für Vegetationskunde. [S.1.: s.n.]: 1975. p. 73-93.

FOOD AND AGRICULTURE ORGANIZATION OF THE UNITED NATIONS. The outlook for 2050 is encouraging, globally, but much work is needed to achieve sustainable water use and ensure food security for all. Rome, 2015. p. 76

FONSECA, H. S.; SALVADOR, N. N. B. Estudo integrado da qualidade das águas da bacia hidrográfica do Rio Bonito em Descalvado - SP. Revista do Instituto Adolfo Lutz, v. 64, n. 2, 2005.

FRANČIŠKOVIĆ-BILINSKI S.; CUCULIĆ V.; BILINSKI H.; HÄUSLER H.; STADLER $\mathrm{Ph}$. Geochemical and stable isotopic variability within two rivers rising under the same mountain, but belonging to two distant watersheds. Chemie der Erde-Geochemistry, v. 73, p. 293-308, 2013.

GOHER, M. E.; HASSAN, A. M.; ABDEL-MONIEM, I. A.; FAHMY, A.H. El-SAYED, S. M. Evaluation of surface water quality and heavy metal indices of Ismailia Canal, Nile River, Egypt. The Egyptian Journal of Aquatic Research, v. 40, p. 225-233, 2014. http://dx.doi.org/10.1016/j.ejar.2014.09.001

HEM, J. D. Study and Interpretation of the chemical characteristics of natural waters. Washington: U.S. Geological Survey, 1970. 363p.

INSTITUTO NACIONAL DE METEOROLOGIA. Website. 2012. Disponível em: www.inmet.gov.br. Acesso em: 2012. 
KEMERICH, P. D. C.; BORBA, W. F.; SILVA, R. F.; BARROS, G.; GERHARDT, A. E.; FLORES, C. E. B. Valores anômalos de metais pesados em solo de cemitério. Revista Ambiente \& Água, v. 7 n. 1, p. 140-156, 2012. http://dx.doi.org/10.4136/ambi-agua.838

LAPPONI, J. C. Estatística usando Excel. 4. ed. Rio de Janeiro: ELSEVIER- CAMPUS, 2005. p. 476.

LEÓN, J. A. C. Calidad de aguas para estudiantes de ciencias ambientales. Bogotá: Universidad Distrital Francisco José de Caldas, 2005.

LOBATO, T. C.; HAUSER-DAVIS, R. A.; OLIVEIRA, T. F.; SILVEIRA, A. M.; SILVA, H. A. N.; TAVARES, M. R. M. et al. Construction of a novel water quality index and quality indicator for reservoir water quality evaluation: a case study in the Amazon region. Journal of Hydrology, v. 522, p. 674-683, 2015. http://dx.doi.org/10.1016/j.jhydrol.2015.01.021

LUCAS, A. A. T.; MOURA, A. S. A; NETTO, A de O. A; FACCIOL, G. G; SOUSA, I. F. Qualidade da água no riacho Jacaré, Sergipe e Brasil usada para irrigação. Revista Brasileira de Agricultura Irrigada, v. 8, n. 2, p. 98-105, 2014. http://dx.doi.org/10.7127/RBAI.V8N200228

MADDEN, N.; LEWIS, A.; DAVIS, M. Thermal effluent from the power sector: an analysis of once-through cooling system impacts on surface water temperature. Environmental Research Letters, v. 8, 2013.

MALHEIROS, C. H.; HARDOIM, E. L.; DE LIMA, Z. M.; AMORIM, R. S. S. Qualidade da água de uma represa localizada em área agrícola (Campo Verde, MT, Brasil). Revista Ambiente \& Água, v. 7, n. 2, p. 245-262, 2012. http://dx.doi.org/10.4136/ambiagua.904

MARIMUTHU, T.; RAJENDRAN, S.; MANIVANNAN, M.. An analysis of efficiency and water quality parameters of dye effluent treatment plant, Karur, Tamilnadu, India. Journal of Environmental Science, Computer Science and Engineering \& Technology, v. 2, n. 3, p. 567-571, 2013.

MARMONTEL, C. V. F.; RODRIGUES, V. A. Parâmetros Indicativos para qualidade da água em nascentes com diferentes coberturas de terra e conservação da vegetação ciliar. Floresta e Ambiente, v. 22, n. 2, p. 171-181, 2015. http://dx.doi.org/10.1590/21798087.082014

MATIC, N.; MIKLAVCIC, I.; MALDINI, K.; DAMIR, T.; CUCULIC, V.; CARDELLINI, C. ET AL. Geochemical and isotopic characteristics of karstic springs in coastal mountains (Southern Croatia). Journal of Geochemical Exploration, n. 132, p. 90-110, 2013. http://dx.doi.org/10.1016/j.gexplo.2013.06.007

MIRANDA, R. G.; PEREIRA, S. de F. P.; ALVES, D. T. V.; OLIVEIRA, G. R. F. Qualidade dos recursos hídricos da Amazônia - Rio Tapajós: avaliação de caso em relação aos elementos químicos e parâmetros físico-químicos. Revista Água \& Ambiente, v. 4, n. 2, 2009. http://dx.doi.org/10.4136/ambi-agua.88 
MONACO, P. A.; MATOS, A. T.; SILVA, N. C. L.; LIMA, C. R. da.; MOREIRA, R. M. Estimativa da concentração de potássio a partir da condutividade elétrica em água residuarias da lavagem e despolpa dos frutos do cafeeiro. Universidade Federal de Viçosa. 2011. Disponível em:

http://www.poscolheita.com.br/poscolheita/Artigos/Meio\%20Ambiente/CONIRD\%20P AOLA\%2011.pdf. Acesso: 8 set. 2012.

OLIVEIRA, B. S. S.de; CUNHA, A. C. da. Correlação entre qualidade da água e variabilidade da precipitação no sul do Estado do Amapá. Revista Ambiente \& Âgua, v. 9, n. 2, p. 261-275, 2014. http://dx.doi.org/10.4136/ambi-agua.1287

PAIVA, L. C.; SOUZA, A. O. Avaliação de alguns parâmetros físico-químicos da água do rio Riachão no município de Caatiba - BA. Enciclopédia Biosfera, v. 6, n. 9, 2010.

PAZ, A. C.; FREDOU, F L.; FREDOU, T. Caracterização da atividade pesqueira em Vila do Conde (Barcarena, Pará), no estuário amazônico. Boletim do Museu Paraense Emílio Goeldi. Ciências humanas, v. 6, n. 2, 2011. http://repositorio.ufpa.br/jspui/handle/2011/3849

PEREIRA, S de F.; LIMA, M. A.; FREITAS, K. H.; MESCOUTO, C. S.; SARAIVA, A. F. Estudo químico ambiental do Rio Murucupi- Barcarena, PA, Brasil área impactada pela produção de alumínio. Revista Água \& Ambiente, v. 2, n. 3, 2007. http://dx.doi.org/10.4136/ambi-agua.34

PONTES, P. P; MARQUES, A. R; MARQUES, G. F. Efeito do uso e ocupação do solo na qualidade da água na micro-bacia do Córrego Banguelo - Contagem. Revista Água \& Ambiente, v. 7, n. 3, p. 183-194, 2012. http://dx.doi.org/10.4136/ambi-agua.962

PIÑEIRO DI BLASI, J. I.; MARTÍNEZ TORRES, J.; GARCÍA NIETO, P. J.; ALONSO FERNÁNDEZ, J. R.; DÍAZ MUÑIZ, C.; TABOADA, J. Analysis and detection of outliers in water quality parameters from 'different automated monitoring stations in the Miño river basin (NW Spain). Ecological Engineering, v. 60, p. 60-66, 2013. http://dx.doi.org/10.1016/j.ecoleng.2013.07.054

RIBEIRO, E. A.; SANDRI, E. A.; BOÊNO, J. A. Qualidade da água de córrego em função do lançamento de efluente de abate de bovino. Revista Brasileira de Engenharia Agrícola e Ambiental, v. 17, n. 4, p. 245-433, 2013. http://dx.doi.org/10.1590/S141543662013000400011

RODIER, J. Analisis de las aguas. Barcelona: OMEGA, 1981. p. 1059.

SÁ FILHO, J. A. R. de. Avaliação qualitativa das águas no sistema da macrodrenagem da Bacia do Tabuleiro do Martins - Maceió/ AL. 2010. Dissertação (Mestrado em Recursos Hídricos e Saneamento) - Universidade Federal de Alagoas, Maceió, 2010.

SANCHEZ, L. E. Avaliação de impacto ambiental: conceitos e métodos. São Paulo: Oficina de Textos, 2006. p. 24.

SANTI, G. M.; FURTADO, C. M.; MENEZES, R. S. A.; KEPPELER, E. C. Variabilidade espacial de parâmetros e indicadores de qualidade da água na sub-bacia hidrográfica do igarapé São Francisco, Rio Branco, Acre, Brasil. Ecologia Aplicada, v. 11, n.1, p. 23-31, 2012. http://dx.doi.org/10.21704/rea.v11i1-2.422 
SANTOS, A. G. da S. dos; MORAES, L. R. S.; NASCIMENTO, S. A. de M. Qualidade da água subterrânea e necrochorumeno entorno do cemitério do Campo Santo em SalvadorBA. Revista Eletrônica GESTA, v. 3, n. 1, p. 39-60, 2015. http://dx.doi.org/10.17565/gesta.v3i1.12456

SILVA, A. E. P.; ANGELIS, C. F.; MACHADO, L. A. T.; WAICHAMAN, A.V. Influência da precipitação na qualidade da água do Rio Purus. Acta Amazonica, v. 38, n. 4, p. 733 742. 2008. http://dx.doi.org/10.1590/S0044-59672008000400017

SIOLI, H. O Rio Arapiuns: estudo limnológico de um corpo d'água da região do terciário, plioceno, série das barreiras, do Baixo Amazonas. Boletim Técnico IAN, p. 3-115, 1956.

SIOLI, H. Pesquisas limnológicas na região da estrada de ferro de Bragança- Estado do Pará- Brasil. Belém: IAN, 1960.

SIOLI, H. Valores de pH de águas amazônicas. Boletim Museo Paraense Emílio Goldie. Geologia, v. 1, p. 1-35, 1957.

SIQUEIRA, G. W.; APRILE, F.; MIGUEIS, A. M. Diagnóstico da qualidade da água do rio Parauapebas (Pará - Brasil). Acta Amazonica, v. 42, n. 3, p. 413-422, 2012. http://dx.doi.org/10.1590/S0044-59672012000300014

SKORONSKI, E. et al. Estudo da aplicação de tanino no tratamento de água para abastecimento captada no rio Tubarão, na cidade de Tubarão, SC. Revista Ambiente \& Água, v. 9, n. 4, p. 679-687, 2014. http://dx.doi.org/10.4136/ambi-agua.1303

SOARES, G. T.; TÁVORA, F.; NUNES. R de O. Índice de qualidade das águas claras, Alvorada do Oeste RO. 2009. TCC (Graduação em Ciências Biomédicas) - Faculdade de Ciências Biomédicas, Cacoal, 2009.

SERAFIN, I. T.; HENKES, J. A. Água de lastro: um problema ambiental. Revista Gestão \& Sustentabilidade Ambiental, v. 2, n. 1, p. 92-112, 2013.

SIOLI, H. Amazônia: fundamentos de ecologia da maior região de florestas tropicais. Petrópolis: Vozes, 1984. 72 p.

SOUZA, J. A. R. de.; MOREIRA, D. A.; CONDÉ, N. M.; CARVALHO, W. B de.; CARVALHO, C. V. M. Análise das condições de potabilidade das águas de surgências em Ubá, MG. Revista Ambiente \& Água, v. 10, n. 3, p. 614-622, 2015. http://dx.doi.org/10.4136/ambi-agua.1630

TUNDISI, J. G.; MATSUMURA TUNDISI, T. Limnologia. São Paulo: Oficina de Textos, 2008. $632 \mathrm{p}$.

UNITED STATES. Environmental Protection Agency - USEPA. Secondary maximum contaminant levels: a strategy for drinking water quality and consumer acceptability. 2015. Disponível em: http://www.waterrf.org/PublicReportLibrary/4537.pdf. Acesso em: set.

UNITED NATIONS ENVIRONMENT PROGRAMME - UNEP. Vital water graphics: an overview of the state of the World's Fresh and marine waters. 2nd Edition. Nairobi, 2008.

VAN NIEKERK, H.; SILBERBAUER, M. J.; MALULEKE, M. Geographical differences in the relationship between total dissolved solids and electrical conductivity in South African rivers. Water SA, v. 40, n. 1, p. 133-137, 2014. 
VASCONCELOS, V. de M. M.; SOUZA, C. F. Caracterização dos parâmetros de qualidade da água do manancial Utinga, Belém, PA, Brasil. Revista Ambiente \& Água, v. 6, n. 2, 2011. http://dx.doi.org/10.4136/ambi-agua.202

VON SPERLING, M. Estudos de modelagem da qualidade da água de rios. Belo Horizonte: UFMG, 2007. Vol. 7. 452 p.

VON SPERLING, M. Introdução à qualidade das águas e ao tratamento de esgoto. 3. ed. Belo Horizonte: UFMG, 2005. 588 p.

ZHANG, Z.; TAO, F.; DU, J.; SHI, P.; YU, D.; MENG, Y. et al. Surface water quality and its control in a river with intensive human impacts - a case study of the Xiangjiang River, China. Journal of Environmental Management, v. 91, p. 2483-2490, 2010. http://dx.doi.org/10.1016/j.jenvman.2010.07.002

ZUIN, V. G.; IORIATTI, M. C. S.; MATHEUS C. E. O emprego de parâmetros físicos e químicos para a avaliação da qualidade de águas naturais: uma proposta para a educação química e ambiental na perspectiva CTSA. Química Nova na Escola, v. 31. 2009. 